\title{
The relationship between the urban rail transit network and the population distribution in Shanghai
}

\author{
Xia Li ${ }^{1, a^{*}}$, Yong Wang ${ }^{2, b}$, \\ ${ }^{1}$ Beijing Jiaotong University, Beijing,China \\ 2 Beijing Jiaotong University, Beijing,China \\ a16120517@bjtu.edu.cn, b15113190@bjtu.edu.cn \\ ${ }^{*} \mathrm{Xia} \mathrm{Li}$
}

Keywords: Urban rail transit network, Population distribution, Coordinated development.

\begin{abstract}
With the development of rail transit projects, the rational distribution of urban rail transit network will help to evacuate the population of the urban area and promote the suburbanization of the population. The change of population distribution will also have a far-reaching impact on the layout of urban rail transit network. Therefore, how to correctly handle the relationship between urban rail transit network and population distribution and achieve the coordinated development has become urgent and important. Based on the connotation of urban rail transit network, this paper establishes an analytical framework for the interaction between urban rail transit network and population distribution. On this basis, the coordination relationship between rail transit network and population distribution in Shanghai is analyzed.
\end{abstract}

\section{Introduction}

The rapid network of urban rail transit has greatly improved the accessibility of spatial location, and has a great impact on the development of urban space. The relationship between rail transit network and the distribution of population tends to close. Under the consideration of economies of scale, the population of the city agglomeration area added rail lines and nodes when it grows to a certain degree, convenient rail transportation in turn will attract more people into the region, which leads to the excessive population agglomeration. Thus, a large number of traffic flows have been generated, causing serious traffic congestion and violating the original intention of developing urban rail transit network. Therefore, only the proper construction and development direction of urban rail transit network can guide the rational distribution of the population, and thus strongly support the expansion of the urban space.

In recent years, urban rail transit is booming in China, and the mode of urban development dominated by rail traffic has become the dominant model. At present, Shanghai rail transit network has developed rapidly, but it has not yet been covered by the whole city. Most of the lines in the peak period still exist overcrowding. In the future, with the development of economic in Shanghai, people who buy and use a car will further increase. In order to alleviate the traffic problems and ensure the sustainable development of the city, we must combine the urban rail transit network with the population distribution in a deeper level to further promote the coordinated development.

\section{The relationship between urban rail transit network and population distribution}

The urban rail transit network has a strong interaction with the population distribution, and the urban rail transit network leads the population distribution as the main aspect. In the early stage of rail transit construction, the main purpose is to meet the needs of residents' travel and relieve traffic congestion. Therefore, rail transit shows the characteristics of "walking along the line", and most of the lines and nodes are located in densely populated areas with large traffic volume. As time goes on, a large number of people gathered in the city center, high population density has led to a series of new 
problems in the city, In order to optimize the urban functions and guide the healthy and orderly development of the city, rail transit has been developed in the population introduction area, so as to enhance the attraction of the suburbs to the population and effectively relieve the central urban population. During this period, the rail traffic tends to fade to the population. The more obvious characteristic is "people follow the line". Therefore, this stage should be guided by the basic line network, coordinating the development of urban rail transit network and population distribution, and realizing the optimization and adjustment of the urban spatial structure.

The development of transportation system can bring greater commuting range to cities, and the characteristics of vehicles determine the distance, accessibility and convenience of residents, and indirectly affect the transformation of urban spatial form through the influence of residents' trip activities. The different times of urban have been dominated by the time, and show distinct characteristics in urban structure, land use, population density and so on.

The distribution of population will also affect the development trend of urban rail transit network. The influence of population distribution on urban rail transit is mainly manifested in the demand of people's traffic. There are great changes in urban residents' traffic demand, such as traffic mode and traffic volume, which accelerates the improvement of urban internal traffic mode and transportation infrastructure construction, thus promoting the evolution of urban air rail transit network.

\section{The coordination relationship between the rail transit network and the population distribution in Shanghai}

The second part elaborates the relationship between the city rail transit network and the population distribution pattern. On the basis of that part, the evolution characteristics of rail transit network and population distribution in Shanghai and the coordination between the two are analyzed in detail.

\subsection{The characteristics and situation of population distribution in Shanghai after 1990s}

There are a large population in Shanghai, but there are obvious regional differences in the spatial distribution of population in each region. In the 1990-2010, the population of Shanghai is highly concentrated in the central city area. Population suburbanization is the process of migration and diffusion of population from the outskirts of the central city, with the phenomenon of rapid development of the population and the suburbs. The population of Shanghai is highly concentrated in the central urban area, and the population density in the suburbs is generally low. The density of the central urban population was 2.26 in the fourth census (1990), the fifth (2000) and the sixth (2010) was 2.35 and 2.37 (10000 person/ $\mathrm{km}^{2}$ ) respectively. The density of the suburban population was as follows: $0.09,0.13,0.13\left(10000\right.$ person $\left./ \mathrm{km}^{2}\right)$. The density of the central urban population was more than 10 times of the suburban. The density of the central urban population was highly concentrated, but the suburban was generally low. In the three census, the population size of the core area respectively is 2.709 million, 2.07 million and 1.778 million. The population size of the core area is significantly reduced.

\subsection{The development of rail transit in Shanghai}

By the end of 2016, there were 14 subway lines that had been opened and operated in Shanghai, and there was a demonstration line of the magnetically levitated train. Since the last century-the first line construction operation began-the rail transit of Shanghai have developed very rapidly, especially after entering twenty-first century. Due to the successful application of Shanghai World Expo in 2002, the comprehensive transportation in Shanghai has been developing continuously under the strong support of the government. The development of rail transportation is also very fast. By the end of 2014, the daily passenger volume of rail transport in Shanghai has reached 7.746 million times. Fig. 1 shows that the daily average passenger volume of rail transit in Shanghai is increasing year by year. 


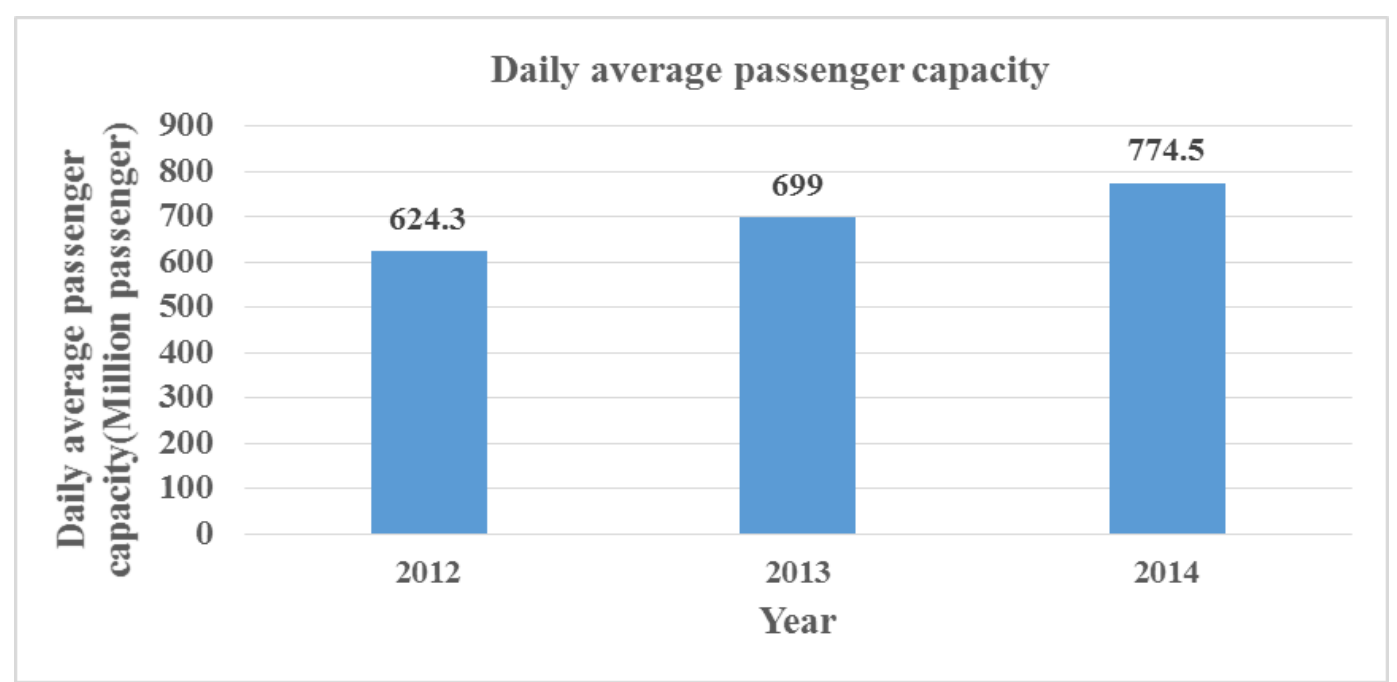

Fig. 1. Daily average passenger capacity.

\subsection{The influence of population distribution on rail transit in Shanghai}

Since the opening of the port to the 20 years before twentieth century, Shanghai is a typical agglomeration city. Urban land distribution is concentrated along the Huangpu River in the Bund as the center. The layout of agglomerated city leads to a high concentration of population, transportation and employment, and traffic congestion. In order to meet the requirements of the urban spatial pattern, save the land resources and reduce the commuter distance, Shanghai chose a simple "chessboard + ring" road network at that time. From 1950s to 1980s, the task of urban planning and construction in Shanghai was to build a satellite town on the periphery of the old urban industry. Such urban population layout has promoted the choice of the "chessboard + ring + ray" traffic network. To some extent, the development of urban suburban area has promoted the construction of radial traffic network, which is beneficial to the connection between central city and satellite towns and suburban towns. The development of high-density cities in old cities has promoted the further improvement of "chessboard + ring" road network.

The urban spatial structure of Shanghai has gradually changed to the multi center city since 1990, and the form of population distribution has also changed greatly. Rail transit has entered Shanghai with its efficiency, convenience, safety, large traffic volume and large urban area. It also promoted the development of Shanghai's "chessboard + belt + double ring" road network. Rail transit has promoted the development of Shanghai's "chessboard + belt + double ring" road network due to its advantages of high efficiency, quick and comfortable safety, large traffic volume and large urban area. First of all, due to the intensified development and opening up in Pudong, Shanghai gradually showed an obvious double center structure. This requires Pudong and Puxi to catch up with the development of the cross river traffic and promote the development of the belt traffic in the east and west. Secondly, from the perspective of large spatial structure, the obvious ring structure of Shanghai has put forward higher requirements for the urban traffic loop. Therefore, the construction of the outer ring road arises at the historic moment. At present, the Shanghai central and suburban lines (A30) have been fully opened to traffic, double traffic pattern has been formed. And, between the cities inside the multi group structural requirements of each group to establish quick transport links, make it become an organic whole, to achieve mutual smooth traffic in the inner city space. In order to achieve this goal, rail transit plays an essential role.

\section{Conclusion}

This paper first analyzes the relationship between urban rail transit network and population distribution, and further explores the mechanism of the relationship, so as to make the foundation for case analysis. Secondly, we analyze the evolution of Shanghai rail transit network and population 
distribution, and reveal the evolution characteristics of rail transit network and population distribution at all stages. Through the analysis of theory and case, the following conclusions are obtained.

The matching of population distribution with the traffic system can be divided into three forms in Shanghai. First, the layout of agglomerated population is "chessboard + ring" traffic network. Second, the population distribution of the urban area and the satellite city is selected "chessboard + ring + ray" traffic network. Third, the population distribution pattern of the circle plus group is the "chessboard + band + double ring" traffic network.

\section{References}

[1] Xiangdong Gao, Min Zheng, and Wenhui Sun, Modelling the Spatial and Structural Distribution of Shanghai Population, Chinese journal of population science, vol.3, pp. 61-66, 2006.

[2] Chunbin Wang and Hokao Kazunori, The Evolution of Population Distribution in Metro City: A Case of Fukuoka City, Japan, Scientia Geographica Sinica, vol.30, pp. 516-520, 2010.

[3] Yongming Zeng, Simulation and Projection on the Pattern of Chinese Population Spatial Distribution: Research with Population Density of County Level Based on the 5th and 6th Population Census of China, Population \& Economics, vol.6, pp. 48-61, 2016.

[4] Tao Li, Xiaoshu Cao, and Xiaoyan Huang, The relationship between spatial structure of accessibility and population change in Pearl River Delta, Geographical Research, vol. 31, pp. 1661-1672, 2012.

[5] Bin Liu, Bingqing Qin, and Zuhua Jiang, UMT and the Optimization of Shanghai Spatial Structure, Int. J. Production Economics, vol. 7, pp. 85-87, 2004.

[6] M. Ben-Daya, M. Darwis, and Xiaoyan Huang, Evaluation of Urban Rail Network Accessibility: A Case Study of Beijing Subway, Urban Studies, vol. 21, pp. 59-60, 2014.

[7] L. Lu, Research on influential factors of population distribution in Henan province based on GWR model, Mathematics in Practice \& Theory, vol. 44, pp. 165-174, 2014.

[8] Xiangdong Sun, and Han Wang, The Evolution of Chinese Floating Population since 2000, Population and Development, vol. 22, pp. 94-104, 2016.

[9] Fu Hu, Jian Sun, and Zhe Li, Development Trend of Shanghai Rail Transit System under Global-City Respective, Urban Development Studies, vol. 2, pp. 6-13, 2016.

[10] Yan Tian, Donghang Yu, and Xiaohu Sun, Study on the influence of Wuhan rail on urban spatial form and population density transit, Urbanism and Architecture, pp. 17-20, 2017.

[11]Chun Zhang, Haishan Xia, and Yan Song, Urban Metro Transit Lead Urban Form Changes: Case Study of Beijing, Urban Development Studies, vol. 23, pp. 107-112, 2016. 